\title{
NASA group urges space station changes to save space science
}

\section{Stanford, California}

FEARS that the continuing fallout from the Challenger accident will have a disastrous impact on space science over the next decade have prompted a NASA (National Aeronautics and Space Administration) science advisory group to recommend urgent new measures to get the space station in operation before 1995 . In particular, the group recommends development of an unmanned heavy lift launch vehicle (HLLV) to launch space station structures, rather than relying solely on the hard-pressed space shuttle.

Events since the Challenger accident have shown that a "fundamentally revised plan of action" is required, according to a recent letter to NASA from Stanford University professor Peter Banks, head of the Task Force on the Scientific Uses of the Space Station.

The group's recommendations were prompted by "desperation", says Michael Wiskerchen, a Stanford senior research associate who is also a member of the task force. He says that steps must be taken now to save the next generation of space scientists and engineers. The committee expressed their concerns to NASA officials during a meeting at Stanford on March 19-20.

The committee recommends that, as well as development of the HLLV, NASA should investigate the possibility of launching a single large core-module to serve as both a laboratory and living quarters, and that it should extend the shuttle's ability to stay in space to two weeks or more.

The task force recommendations were initially received less than enthusiastically by NASA officials. Robert Naumann, chief scientist for the space station, responded to Banks saying that "if we wish to see an operational space station in our professional lifetime, the only option is to continue on our present course. Unless we all pull together on this, I'm afraid we will wind up with nothing."

The task force supports the space station concept, but is worried about the effects of delays on the future of space science and is urging NASA to study its proposals in parallel with present plans for the space station so as to be able to take advantage of an HLLV if one is developed.

NASA recently completed a study of an HLLV, but has not received authority to develop such a vehicle; Naumann doubts that one could be operational by 1992 . But members of the Banks committee say that private industry could have an HLLV ready by 1992 . Banks's letter also says that access to the space environment is the "single most pressing issue of the next decade" for the space science community. NASA's present plan to have the station operational by $1995-96$ is "too late to help," he says.

While an extension of the duration of shuttle flights to $14-17$ days from the present 7-day limit would "double the productivity of many missions ....", Banks's advocacy of the development of an HLLV for launching elements of the space station stems directly from concerns about the Shouldn't one of us try to wake her with a kiss?

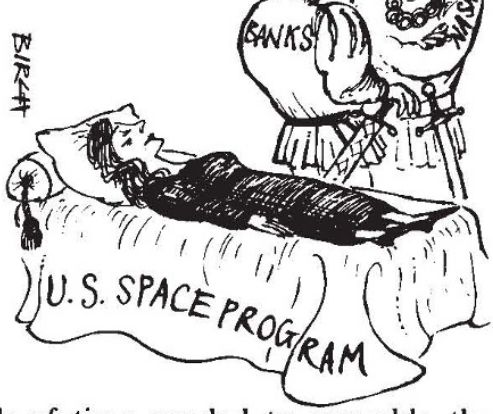

length of time needed to assemble the station and to commission it if only the shuttle is available.

NASA's present plans call for a dozen or more shuttle flights to launch and assemble several smaller research and living modules. Wiskerchen said that the committee did not recommend that this plan should be abandoned, but that the large core module concept should be studied as well so that an informed choice between the two could be made if an HLLV programme is started.

Although there have been rumblings in the space science community that unmanned missions could accomplish most scientific objectives, Banks says there is still an important role for man in space, and that the proposed large-core module would permit laboratory-style research programmes that could not be done with automated systems.

Lydia Dotto

- An Atlas-Centaur rocket launched from Cape Canaveral during a rainstorm on 26 March veered off course approximately 52 seconds after lift-off and was destroyed by ground controllers. The Atlas-Centaur was carrying a military communications satellite. NASA is seeking to recover the rocket's digital control unit to determine whether lightning may have contributed to the launch failure.

Initial investigations by NASA indicate that lightning was observed near the rocket at approximately the same time things started to go wrong with the flight. At 49 seconds after launch, the AtlasCentaur's guidance system detected and
Indian rocket failure hits space programme New Delhi

THE crash last week of a US\$100 million Indian rocket on its maiden flight and carrying a scientific satellite is a major setback to the country's space programme. The spacecraft went into the sea just two minutes after its launch from the Sriharikota launch pad and was witnessed by the Prime Minister, Mr Rajiv Gandhi.

The 40-tonne augmented satellite launch vehicle (ASLV) is believed to have fallen into the Bay of Bengal intact except for the two strap-on boosters, the only parts that seemed to work during the mission.

The four-stage ASLV was the first of India's second-generation rockets incorporating strap-on technology. It was also the first to use a closed loop guidance system for accurate ejection of payload in a predetermined orbit. The prevous launcher, SLV-3, could lift only $50 \mathrm{~kg}$ of payload; with the addition of two boosters, carrying a total of 17 tonnes of solid fuel, ASLV's payload capability is $150 \mathrm{~kg}$.

The prime minister was stoical after the failure, telling the team responsible not to be disheartened. "It is a small stumble, but work must go on", he said.

According to Professor U. R. Rao, chairman of the Space Commission, the mission failed after the strap-on boosters burned out and separated and before the ignition of the first stage. What happened subsequently was not immediately known as the telemetry failed. He said the exact cause of the crash would be known only after several days.

The rocket was intended to place a 150 . kg satellite into a $400-\mathrm{km}$ nearly circular orbit. The satellite carried scientific equipment to measure gamma-ray bursts. There is no plan to recover the satellite or the rocket from the sea.

The abortive launch is expected to delay other projects. India had planned to launch in 1989 a polar satellite launch vehicle using a liquid-fuelled engine, followed by a geostationary satellite launch vehicle using cryogenic engines in 1992. Last week's failure is likely to lead to a revision of the schedule. K.S.Jayaraman

then attempted to correct for a nonexistent trajectory error. At 59 seconds, the launch vehicle began to break up, and ground controllers destroyed it. Although it was raining at the time of the launch. NASA officials say no lightning had been observed for the previous 12 minutes, and conditions were acceptable for launch.

This was the 67th Atlas-Centaur launch and the programme has had a 90 per cent success rate. The last Atlas-Centaur launch in December 1986 was a success, carrying another military communications satellite. 